\title{
Quantification of Atropine in Leaves of Atropa belladonna: Development and validation of method by high-perfomance liquid chromatography (HPLC)
}

\author{
Mariana Koetz ${ }^{\mathrm{a}_{*}}$, Thalita G. Santos ${ }^{\mathrm{b}}$, Magda Rhayanny ${ }^{\mathrm{c}}$, Amélia T. Henriques ${ }^{\mathrm{a}}$
${ }^{a}$ Laboratório de Farmacognosia e Controle de Qualidade Farmacêutica, Faculdade de Farmácia, Universidade Federal do Rio Grande do Sul - UFRGS, Av. Ipiranga, 2752, 90610-000, Porto Alegre/RS, Brazil \\ ${ }^{b}$ Laboratório de Farmacognosia, Faculdade de Farmácia, Universidade Federal do Paraná - UFPR, Avenida Pref \\ Lothario Meissner, 3400, 80210-170 - Jardim Botânico, Curitiba/PR, Brazil \\ ${ }^{c}$ Laboratório de Farmacognosia, Faculdade de Farmácia, Universidade Federal do Pernambuco - UFPE, Av. Professor \\ Arthur de Sá, 50740-521 Recife/PE, Brazil \\ *Corresponding author e-mail: mkoetz@gmail.com/mariana.koetz@ufrgs.br
}

\begin{abstract}
The leaves of Atropa belladonna (L) are characterized by the presence of the alkaloid atropine, known for the antimuscarinic activity. They are used in therapy, mainly in homeopathic preparations. An HPLC method was developed and validated to quantify atropine in belladonna leaves. The samples were extracted with methanol, followed by acidbase extraction with $5 \% \mathrm{HCl}$ and dichloromethane. Analysis by HPLC was performed on C18 column, in a linear gradient system using two mobile phases (water and acetonitrile), both acidified with trifluoroacetic acid. The determinations were performed using a reference standard and a diode array detector at $210 \mathrm{~nm}$. The method was validated and proved to be specific/selective, comparing the UV profiles and the purity of the atropine peaks in reference and sample solutions and analyzing sample solutions with and without addition of standard, which produced an increase only of the area of peak of the sample, without changing the area of the adjacent peaks. The linearity $(50-200 \mu \mathrm{g} / \mathrm{mL})$ was provided by analysis of the analytical curves of atropine, with $\mathrm{r} 2=0.9996$. LOD and LOQ were 3.75 and 11.4 $\mu \mathrm{g} / \mathrm{ml}$, respectively. The method was precise, reproducible and accurate, and presented recovery equal to $103.0 \%$. The method was considered robust for the analyzed parameters. Four commercial samples were analyzed and the mean levels of atropine found ranged from $0.16-0.27 \%$. Thus, the method developed is effective for atropine quantification in $A$. belladona leaves, because meets validation requirements of current legislation, besides presenting itself as a useful tool in the control of the quality of this plant material.
\end{abstract}

Keywords: Atropa belladonna; Atropine; HPLC method, Validation; Quality Control.

\section{Introduction}

Atropine is a tropane alkaloid that plays an important role in therapy because of its inhibitory action on acetylcholine. These metabolites are known as antimuscarinic or blocking substances of cholinergic muscarinic receptors. Although it can be performed by synthetic route, obtaining this metabolite is still performed from natural sources, mainly from plants of the Solanaceae family, such as Atropa Belladonna L., which present atropine as the major compound in its composition (1-4).

Scientific studies have been increasingly driven to develop analytical methodologies for the quantification of chemical markers in plant materials, resulting in quality materials that meet the control parameters recommended by the legislation due to the importance of raw materials of plant origin and plant medicines for the pharmaceutical industry. Plant medicines used as raw material in the production of herbal medicinal products should be subjected to qualitative and quantitative analysis of the active ingredients and / or chemical markers, when known. The methodologies developed and used in official compendia (pharmacopoeias) must be validated and all validation steps (specificity/selectivity, linearity, limits of detection (LOD) and quantification (LOQ), precision, precision and robustness) must be proven (5-9). The official compendia describe the determination of total alkaloids in A. belladonna by titration method (10-12) and also by gas chromatography (13), but these methods employ large amounts of solvents, mainly in the extraction stage and are difficult to reproduce.

Developing analytical methods that are capable of identifying, separating or quantifying analytes in plant materials becomes a challenge, given the complexity of the matrices of these materials (14-16). Several authors describe methods to quantify tropane alkaloids in the Solanaceae Family's plant raw materials, with emphasis on Datura, Atropa and Hyosciamus species. Among the 
techniques used, High Performance Liquid Chromatography (HPLC) is the most widely developed for this purpose (17-24). Buffered mobile systems or having only one salt dissolved in their composition $\left(\mathrm{K}_{2} \mathrm{HPO}_{4}, \mathrm{KH}_{2} \mathrm{PO}_{4}\right.$, for example) are best described for quantifying tropic type alkaloids (18-23). Ashtiania and Sefidkonb (2011) (21) quantified total alkaloids (atropine and scopolamine) in A. belladonna leaf cultures using these systems. In 2005, Kursinszki and colleagues (24) developed a method, without using mobile phase systems with buffer solution, to quantify these alkaloids in cultivated roots of this species. Thus, a quantitative method to determine atropine in this plant drug becomes interesting considering the importance of guaranteeing the quality of this material for its use in the industry.

\section{Experimental}

\section{Chemical and Standard}

All solvents (HPLC and analytical grade) were purchased from Tedia (Fairfield, CA, USA). Chemical Standard of atropine ( $\geq 99 \%$ ) (Figure 1) was purchased from Sigma-Aldrich (São Paulo, Brazil). The other analytical grade reagents were purchased from F. Maia (Cotia, SP, Brazil) and Vetec (Duque de Caxias, RJ, Brazil).

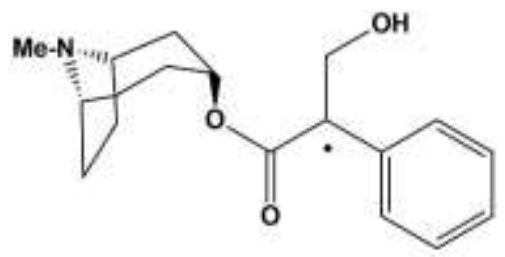

$$
\begin{aligned}
& (\mathrm{R})-(+) \text { - Hiosciamina } \\
& (\mathrm{S})-(+) \text { - Hiosciamina }
\end{aligned}
$$

Figure 1 Chemical structure of atropine.

\section{Plant material and sample preparation}

Four samples the A. belladonna leaves were commercially available and named Ab-01, Ab-02, Ab03 and Ab-04. The sample Ab-01 was used to develop and validate the method. Approximately $0.25 \mathrm{~g}$ of the powdered drug (particle size - $180 \mu \mathrm{m}$ ) was weighed accurately in $50 \mathrm{ml}$ erlenmeyer flask and $15 \mathrm{ml}$ of methyl alcohol was added. The flask was closed with plastic film and taken to the ultrasonic bath for 60 minutes $(25,26)$. The crude methanolic extract was filtered through filter paper into a $50 \mathrm{~mL}$ round bottom flask. The Erlenmeyer flask was washed with 2 x $1 \mathrm{~mL}$ methyl alcohol p.a. The solvent was removed on a rotary evaporator without exceeding $40{ }^{\circ} \mathrm{C}$. The dried extract of the flask was transferred to a $250 \mathrm{~mL}$ separatory funnel using $25 \mathrm{~mL}$ of $5 \%$ hydrochloric acid $(5 \% \mathrm{HCl})$ with ultrasonic aid to facilitate the solubilization of the extract in acid medium. The aqueous acid phase was extracted with $3 \times 20 \mathrm{~mL}$ dichloromethane using the first $20 \mathrm{~mL}$ to clear the residue from the $50 \mathrm{~mL}$ round bottom flask. The organic phases of the washes were discarded. The aqueous extract was basified with ammonium hydroxide $(25 \%$ $\mathrm{NH}_{4} \mathrm{OH}$ ) to $\mathrm{pH} 10$. The alkaloids were extracted with 5 x $20 \mathrm{~mL}$ of dichloromethane. The organic phases were combined and dried with $15 \mathrm{~g}$ of anhydrous sodium sulfate. Then it was filtered through filter paper into a porcelain crucible, the sodium sulfate from the filter paper was washed with $2 \mathrm{ml}$ of dichloromethane. The solvent was evaporated to dryness in a water bath, without exceeding $40{ }^{\circ} \mathrm{C}$. The dry extract of alkaloids was solubilized with methanol into a $5 \mathrm{~mL}$ volumetric flask and filtered through a $0.45 \mu \mathrm{m}$ membrane into a 2 $\mathrm{mL}$ vial.

\section{Instrumentation and HPLC Conditions}

The atropine analyses were performed using a Waters-Alliance 2695 equipped with a photodiode array detector (PDA) and an Empower software for data processing. Chromatographic separation was carried out in a Kromasil C18 column ( 150 x 4,6 mm i.d.; particle size, $5,0 \mu \mathrm{m})$ guarded by a pre-column filter in-line Ultra (Phenomenex, USA). The mobile phase was composed of water (A) and acetonitrile (B), acidified with 0.01 e $0.08 \%$ trifluoracetic acid (v/v), respectively, filtered through a $0.45 \mu \mathrm{m}$ porous nylon membrane and degassed in ultrasonic bath for 30 minutes. The gradient profile was adjusted as follows: $0.00 \mathrm{~min}$. $5 \%$ eluent B, 15.00 minutes eluent $100 \%$ B. After isocratic elution was carried out up to $20.00 \mathrm{~min}$ eluent $100 \% \mathrm{~B}$. Between the injections a $10 \mathrm{~min}$ equilibrium was performed using 5\% B eluent. Sample were injected with auto-sampler in a volume of $10 \mu \mathrm{L}$. Eluent system was pumped at a flow rate of $0.7 \mathrm{~mL} / \mathrm{min}$ and detection wavelength was set to $210 \mathrm{~nm}$.

\section{Method Validation}

\section{System Suitability}

Tests were performed to verify the adequacy of the chromatographic system for the analysis. During validation, peak area parameters, retention time and number of plates, referring to the peak atropine standard, were analyzed and evaluated by the relative standard deviation of the measurements on the different validation days.

\section{Specificity/Selectivity}

The data were obtained by comparing the ultraviolet profile and the purity of the atropine peak from the injection of the standard atropine solution $(125 \mu \mathrm{g} / \mathrm{mL})$ and the sample solution and analyzing the areas of atropine in solution of the sample with and without addition of standard atropine. 
Linearity and Limits of Detection and Quantification (LOD e $L O Q$ )

Performed by injecting different dilutions of a stock solution of atropine standard $(500 \mu \mathrm{g} / \mathrm{mL})$. Three curves of the reference substance were constructed on different days with 7 points (injected in triplicate), corresponding to a concentration range of atropine between 50 and 200 $\mu \mathrm{g} / \mathrm{mL}$. The linearity of the method was verified from the measurement of the area of the peak referring to the chemical marker in the chromatogram. The regression coefficient was evaluated and the statistical treatment was performed using the least squares method and analysis of variance.

LOD and LOQ were calculated from the data obtained in the linearity study and through Equations: $\mathrm{LOD}=(3.3 \times \mathrm{s}) / \mathrm{I}$ and $\mathrm{LOQ}=(10 \mathrm{x} \mathrm{s}) / \mathrm{I}$, at were, $\mathrm{s}=$ Mean standard deviation of the intercept of the three curves and I = Average slope of the three curves.

\section{Precision}

Repeatability (intra-days) was performed by analyzing six extracts from the sample, injected in triplicate in HPLC.

Intermediate precision (inter-days) was performed by analyzing, on three different days, three extracts were prepared and injected in triplicate on HPLC.

Interlaboratory reproducibility was performed in collaboration with the pharmacognosy laboratories of the Federal Universities of Paraná (UFPR) and of Pernambuco (UFPE). The sample and standard atropine were sent for analysis along with protocol describing the methodology. The analyzis were performed in triplicate and the results found were compared and the DPR was calculated among the means of the determinations in the different laboratories. Atropine levels and the relative standard deviation (RSD) of the means were evaluated.

\section{Accuracy}

Standard atropine solution at concentrations of 80 , 100 and $120 \%$ (relative to the extraction of plant material) was added at the final stage of the extraction process. The levels recovered from atropine and RSD of the means was evaluated.

\section{Robustness}

Performed by modifying previously established parameters of analysis. The atropine levels were calculated and the RSD and relation to the normal condition analysis was evaluated. The modified parameters were: mobile phase flow $( \pm 0,05 \mathrm{~mL} / \mathrm{min})$; Wavelenght $( \pm 5 \mathrm{~nm})$ and column supplier (Nano Separation Technologies - NST).

\section{Analysis of Commercial Samples}

Samples Ab-01, Ab-02, Ab-03 and Ab-04 were prepared as described in item 2.2 and analyzed in the developed and validated method.

\section{Results}

\section{Method Development}

In the development of the method, the standard and sample solutions produced the chromatograms shown in Figure 2, were it is possible to identify the atropine peak at the retention time of approximately 7.7 minutes.

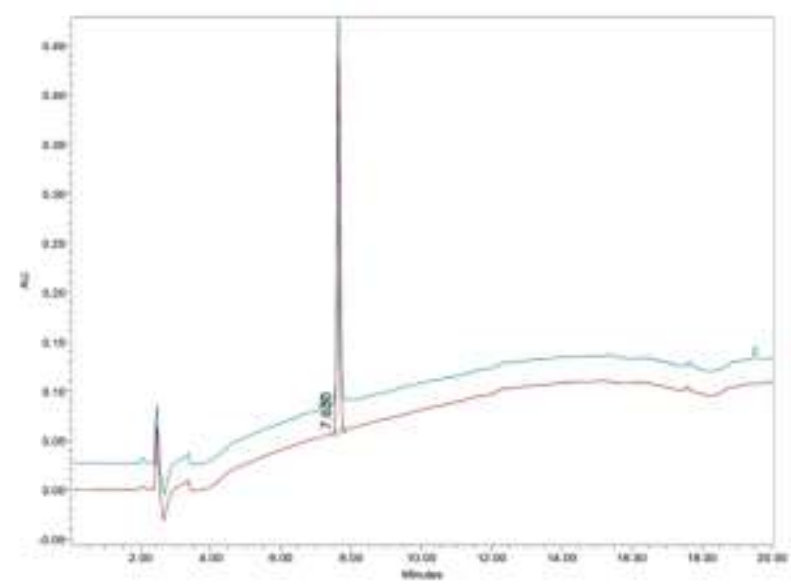

Figure 2 Overlay chromatogram of the atropine sample and standard solutions.

\section{Method Validation}

\section{System Suitability}

The routine analysis of the atropine standard was achieved under the conditions of the method developed by HPLC. The parameter values and their relative standard deviation (RSD\%) are shown in Table 1. In summary, the results for each parameter demonstrated that the system is suitable for atropine analysis.

Table 1 Results of system suitability for atropine quantification method in A. belladonna leaves.

\begin{tabular}{clcc}
\hline Compound & \multicolumn{1}{c}{ Parameter } & Mean & RSD (\%) \\
\hline \multirow{4}{*}{ Atropine } & $\begin{array}{l}\text { Retention Time } \\
(\mathrm{min})\end{array}$ & 7.691 & 0.8008 \\
& $\begin{array}{l}\text { Number of plates } \\
(\mathrm{N})\end{array}$ & 15231.2 & 3.523 \\
& Peak Area (mV.s) & 1971669 & 1.114 \\
\hline
\end{tabular}




\section{Specificity / Selectivity}

The specificity/selectivity was evidenced with UV profiles of the atropine peak in similar reference and sample solutions, as well as the observation of the peak purity shown in Figure 3 ( $a$ and $b$ ). The selectivity was confirmed by the addition of a reference substance in the sample solution, which produced an increase only in the peak area of the sample, without changing the area of the adjacent peaks (Figure 3c). The areas measured before and after standard addition were 892459 and 1964117 for the atropine peak and there was no change in the other areas of the chromatogram. It was possible through the tests to observe that the method is specific and selective for analysis of the metabolite under study

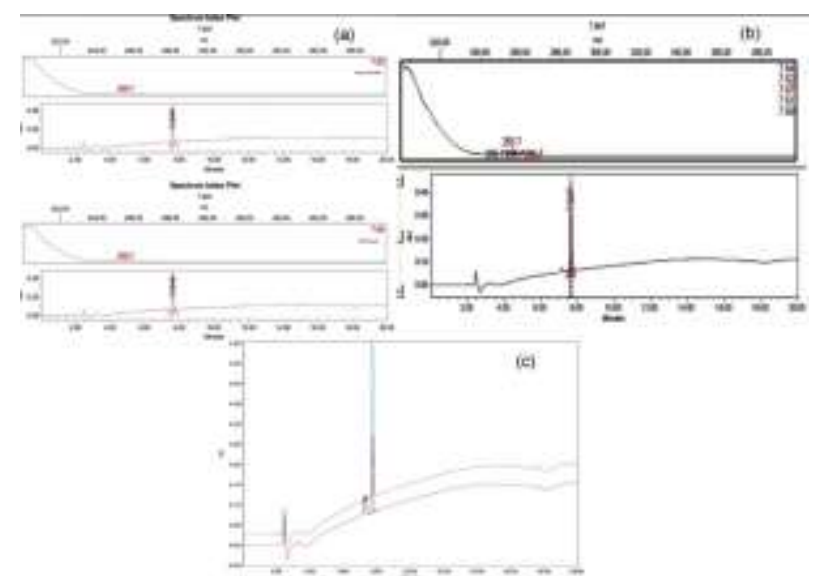

Figure 3 (A) UV profile of the atropine sample solution and the standard; (B) Peak purity of atropine sample solution; (C) Overlay chromatogram of the atropine sample solution with and without addition of atropine standard.

\section{Linearity, $L O D$ and $L O Q$}

Was determined of reference solutions with concentrations range $50-200 \mu \mathrm{g} / \mathrm{mL}$, with regression equation $\mathrm{Y}=15490 \mathrm{x}+18019$ and $\mathrm{r}^{2}=0.9996$. LOD and LOQ were 3.75 and $11.3 \mu \mathrm{g} / \mathrm{ml}$, respectively. The values obtained in the analysis of variance (ANOVA) show that there are significant differences between the different concentrations and respective areas (P-value $<0.05$ and F $>$ Fcritic), with a confidence interval of $95 \%$ $(\alpha=0.05)$.

\section{Precision}

The method proved to be precise, with mean atropine levels of $0.267 \%$ and RSD equal to $2.78 \%$ for repeatability and intermediate steps. The results of Interlaboratory Reproducibility were also satisfactory, since the mean amount between laboratories was equal to $0.262 \%$ with RSD of $1.38 \%$. Table 2 presents the results of this validation step.
Table 2 Results the precision step for atropine quantification method in A. belladonna leaves.

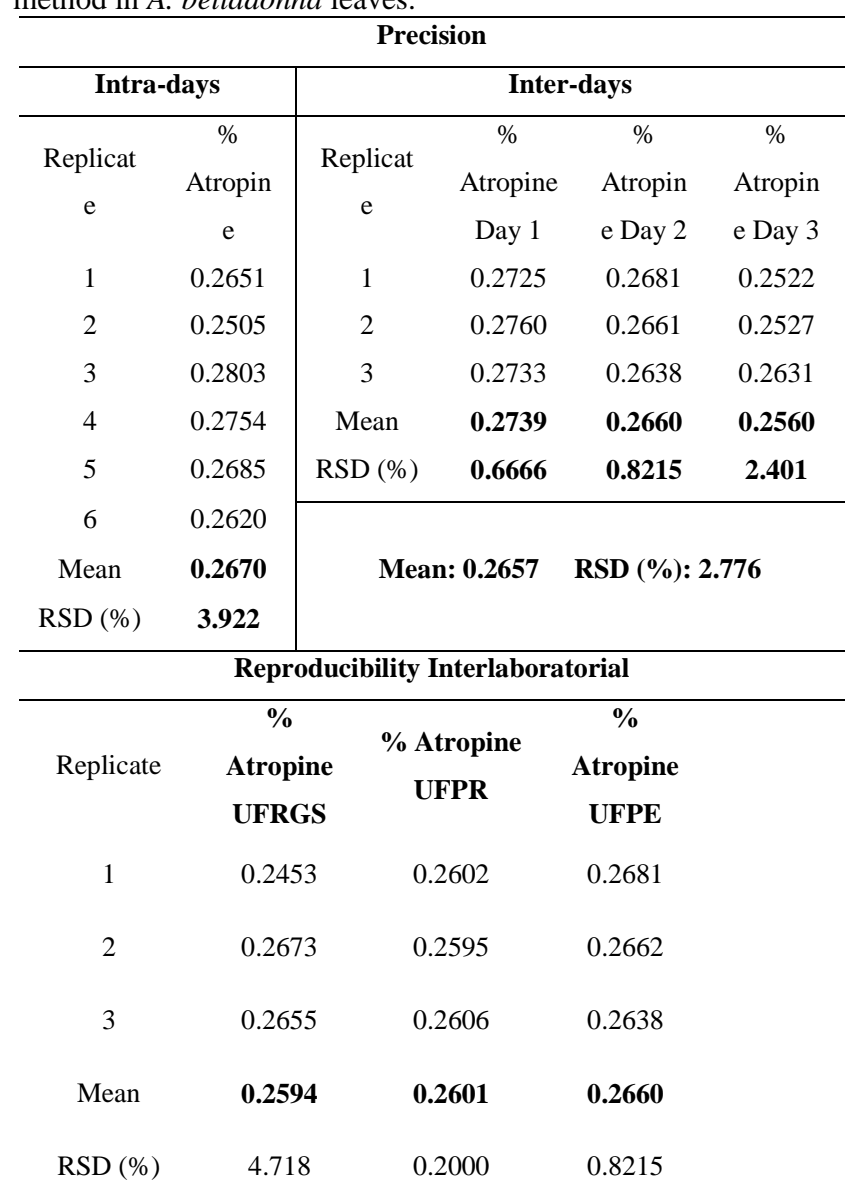

Mean: $0.2618 \%$

RSD (\%): $1.34 \%$

\section{Accuracy}

The recovered levels of atropine standard are shown in table 3. The mean recovery of method was $103.0 \%$ with RSD of less than $5 \%$, according to the official guidelines. In this way, developed method can be considered accurate.

Table 3 Results the recovery study to evaluate accuracy for atropine quantification method in A. belladonna leaves.

\begin{tabular}{lccc}
\hline Solution & $\begin{array}{c}\text { Standard } \\
\text { Added } \\
(\mu \mathrm{g} / \mathrm{mL})\end{array}$ & $\begin{array}{c}\text { Experimental } \\
\text { Concentration } \\
(\mu \mathrm{g} / \mathrm{mL})\end{array}$ & $\begin{array}{c}\text { Average Recovery } \\
(\%)\end{array}$ \\
\hline SS $^{*}$ & - & 56.02 & - \\
$\mathrm{ASS}^{*}$ & 55.10 & - & - \\
$\mathrm{RS}^{*}{ }^{*}$ & 44.08 & 100.7 & 101.4 \\
$\mathrm{RS}^{*} 00^{*}$ & 55.10 & 112.9 & 103.3 \\
$\mathrm{RS} 120^{*}$ & 66.12 & 125.0 & 104.4 \\
\hline & & Mean & 103.0 \\
& & RSD $(\%)$ & 1.484
\end{tabular}

${ }^{*}$ SS - Sample Solution; ASS - Atropine Standard Solution; RS80,100,120 - Recoverys Solutions 80, 100, $120 \%$ 


\section{Robustness}

The method was robust, considering that no altered parameter produced a RSD result higher than $5 \%$ in relation to the mean atropine content of the analyzes under normal conditions. Table 4 shows the results obtained in the method validation step.

Table 4 Results of robustness step for atropine quantification method in A. belladonna leaves.

\begin{tabular}{lcc}
\multicolumn{1}{c}{ Variation } & Atropine $(\%)$ & RSD (\%) \\
\hline Mobile phase flow $(0.65$ & 0.2641 & 3.123 \\
$\mathrm{~mL} / \mathrm{min})$ & 0.2531 & 0.1125 \\
Mobile phase flow $(0.75$ & & \\
$\mathrm{mL} / \mathrm{min})$ & 0.2516 & 0.3123 \\
Wavelength $(\lambda=205 \mathrm{~nm})$ & 0.2498 & 0.7992 \\
Wavelength $(\lambda=215 \mathrm{~nm})$ & 0.2564 & 1.020 \\
Colunm supplier $(\mathrm{NST})$ & & \\
\hline
\end{tabular}

RSD calculated relative to the normal analysis condition

\section{Analysis of Commercial Samples}

Analysis of commercial samples revealed levels varying from 0.16 to $0.27 \%$ of atropine (Table 5), indicating marked variability between the different samples.

Table 5 Analysis result of atropine content in commercially obtained samples.

\begin{tabular}{ccccc}
\hline Replicate & $\begin{array}{c}\text { Ab-01 } \\
(\% \\
\text { atropine })\end{array}$ & $\begin{array}{c}\text { Ab-02 } \\
(\% \\
\text { atropine })\end{array}$ & $\begin{array}{c}\text { Ab-03 } \\
(\% \\
\text { atropine })\end{array}$ & $\begin{array}{c}\text { Ab-04 } \\
(\% \text { atropine })\end{array}$ \\
\hline 1 & 0.2681 & 0.2051 & 0.1556 & 0.2769 \\
2 & 0.2662 & 0.2100 & 0.1570 & 0.2705 \\
3 & 0.2638 & 0.1931 & 0.1686 & 0.2702 \\
Mean & $\mathbf{0 . 2 6 6 0}$ & $\mathbf{0 . 2 0 2 7}$ & $\mathbf{0 . 1 6 0 4}$ & $\mathbf{0 . 2 7 2 6}$ \\
RSD (\%) & 0.8215 & 4.2973 & 4.4572 & 1.3918 \\
\hline
\end{tabular}

\section{Conclusion}

Considering the reports of determination of this type of secondary metabolite, using HPLC, in different plant materials, it was possible to obtain a method successfully developed for this purpose. The developed method was validated, showing precision, accuracy and robustness, with all the steps presenting RSD results below $5 \%$.

A. belladonna is a plant material widely used in therapeutics and, since official quantification methods involve titration techniques or gas chromatography, the method developed in this work is advantageous because it uses a technique that quantifies in a simple, fast and efficient way of the active in the plant drug, can be applied to the quality control routines, of the studied plant drug, with confidence.

\section{Acknowledgments}

This work was possible with the financial support of the Brazilian Pharmacopoeia and infrastructure of the Pharmacognosy Laboratory of Faculty of Pharmacy of Federal University of Rio Grande do Sul.

\section{References}

1. Tyler, V.E., Brady, L.R., Robbers, J.E. Pharmacognosy. Lea and Febiger, 9th ed. Philadelphia: 1988.

2. Morales, R. Plantas y Cultura Popular: La Etnobotánica em España. Quercus. 1995:7-8.

3. Hernandes, L.S., Kato, E.T.M., Bacchi, E.M. Alcaloides Tropânicos. In: SIMÕES CMO et al. Farmacognosia: do produto natural ao medicamento. 1. ed. Porto Alegre: Artimed, 2017, p.349-365.

4. Grynkiewicz, G., Gadzikowska, M. Review of Tropane alkaloids as medicinally useful natural products and their synthetic derivatives as new drugs. Pharm Reports 2008; 60:439-463.

5. Brasil. Ministério da Saúde. Agência Nacional de Vigilância Sanitária. Resolução RE nº 899 de 29 de maio de 2003. In: Diário Oficial da União, Brasília, 02 jun. 2003.

6. ICH. International Conference of Harmonization of Technical Requeriments for Registration of Pharmaceuticals for Human Use. Validation of Analytcal Procedures: Text and Methodoly. Q2(R1). 2005:12 p.

7. USP. The United State Pharmacopeia. NF 38. 34. ed. Rockville: Estados Unidos Pharmacopeial Convention, 2015:1445-1451.

8. Brasil. Ministério da Saúde. Agência Nacional de Vigilância Sanitária. Resolução RDC no. 14 de 31 de março de 2010. In: Diário Oficial da União, Brasília, 05 abr. 2010.

9. Toomula, N. et al. Development and Validation of Analytical Methods for Pharmaceuticals. J Anal Bioanal Techn 2011. 2:4.

10. British Pharmacopea. Herbal Drugs. 2014. IV:8688 .

11. Farmacopeia Brasileira. Agência Nacional de Vigilância Sanitária. 5ed. Brasília. 2010; 2:679-682.

12. Real Pharmacopea Española. 2e d. 2002: 805-806.

13. USP. The United State Pharmacopeia. NF 37. 33. ed. Rockville: Estados Unidos Pharmacopeial Convention, 2014: 1921-1923. 
14. Vilegas, W., Cardoso, C.A.L., Quevedo, A.E.P. Controle Químico de Qualidade de Fitoterápicos e Plantas Medicinais. In: Yunes RA, Filho VC (Orgs.). Química de Produtos Naturais: novos fármacos e a moderna farmacognosia. 5.ed. Itajaí: Ed. Univali, 2016, p.185-214.

15. Srivastava, M.M. HPTLC: High-Performance ThinLayer Chromatography. Ed. Springer, 2011.

16. Reginatto, F.H. Introdução à análise fitoquímica. In: Simões CMO et al. Farmacognosia: do produto natural ao medicamento. 1. ed. Porto Alegre: Artimed, 2017, p. 69-81.

17. Mroczek, T., Glowniak, K., Kowalska, J. Solidliquid extraction and cation-exchange solid-phase extraction using a mixed-mode polymeric sorbent of Datura and related alkaloids. J Chromatogr A, 2006; 1107:9-18.

18. Chem, H., Marín-Sáez, J., Romero-Gonzáles, R., Frenish, A.G. Simultaneous determination of atropine and scopolamine in buckwheat and related products using modified QuEChERS and liquid chromatography tandem mass spectrometry. Food Chemistry. 2017; 218:173-180.

19. Temerdashev, A.Z., Kolychev, I.A., Kiseleva, N.V. Chromatographic determination of some tropane alkaloids in Datura metel. J. anal. chem. 2012; 67:960 966.

20. Ashtiania, F., Sefidkonb, F. Tropane Alkaloids of Atropa Belladonna L. and Atropa acuminate Royle ex Miers plants. J. Medic. Plants Research. 2011; 5:65156522 .

21. Bazaoui, A., Belliman, M.A., Soulaymani, A. Nine new tropane alkaloids from Datura stramonium L. identified by GC/MS. Fitoterapia. 2011; 82:193-197.

22. Ceyhan, T., Kartal, M., Altun, M.L., Tümelis, F., Cevheroglu, S. LC determination of atropine sulfate and scopolamine hydrobromide in pharmaceuticals. J. Pharm. and Biom. Anal. 2001; 25:399-406.

23. Hank, H., Szöke, É., Tóth, K., László, I., Kursinszki, L. Investigation of Tropane Alkaloids in Genetically Tranformade Atropa Belladonna L. Cultures. Chromatographia, 2004; 60:55-59.

24. Kursinszki, L., Hank, H., Lázló, I., Szöke, É. Simultaneous analysis of hyosciamine, scopolamine, $6 \beta$-hydroxyhyosciamine and apoatropine in Solanaceous hairy roots by reversed-phase hight-performance liquid chromatography. J. Chromatogr. A, 2005; 1091:32-39.

25. Klein-Júnior, L.C., Heyden, I.V., Henriques, A.T.H. Enlarging the bottleneck in the analysis of alkaloids: A review on sample preparation in herbal matrices. Trends and Anal. Chem. 2016; 80:66-82.
26. Picó, Y. Ultrasound-assisted extraction for food and environmental samples. Trends and Anal. Chem. 2013; 43:84-99. 